\title{
We see things not as they are but as we are
}

Colin M. Barker, MD, ${ }^{\mathrm{a}}$ and Michael J. Reardon, $\mathrm{MD}^{\mathrm{b}}$

\author{
From the Departments of ${ }^{\mathrm{a} C}$ ardiology and ${ }^{\mathrm{b}}$ Cardiovascular Surgery, Houston Methodist Hospital, Houston, Tex. \\ Disclosures: Authors have nothing to disclose with regard to commercial support. \\ Received for publication May 30, 2018; revisions received May 30, 2018; accepted for publication May 31, 2018; \\ available ahead of print July 26, 2018. \\ Address for reprints: Michael J. Reardon, MD, Department of Cardiovascular Surgery, Houston Methodist Hos- \\ pital, 6550 Fannin, Suite 1401, Houston, TX 77030 (E-mail: mreardon@houstonmethodist.org) \\ J Thorac Cardiovasc Surg 2018;156:1813 \\ $0022-5223 / \$ 36.00$ \\ Copyright $(2018$ by The American Association for Thoracic Surgery \\ https://doi.org/10.1016/j.jtcvs.2018.05.117
}

Left ventricular pseudoaneurysm can occur after myocardial infarction, previous cardiac surgery, trauma, and infection. The major indications for repair are the potential for rupture, arrhythmias, and heart failure caused by the paradoxical expansion of the pseudoaneurysm during systole stealing forward flow. Successful surgical repair requires the surgeon to address these concerns. This usually entails direct or patch closure of the opening of the pseudoaneurysm to eliminate the risk of rupture and convert the paradoxically expanding pseudoaneurysm sac into a stable, akinetic area while maintaining ventricular geometry. These aneurysms are usually approached from the external cardiac surface, opening the pseudoaneurysm sac, identifying the opening, and closing in an appropriate manner. In this issue of the Journal, Drs Charles and Crestanello ${ }^{1}$ describe a postmyocardial infarction left ventricular pseudoaneurysm that occurred with patent saphenous vein grafts and a patent left thoracic graft attached to the pseudoaneurysm sac. They describe a clever internal repair in a transaortic valve fashion that allowed them to complete the repair accomplishing the principles listed while avoiding the patent bypass grafts and the potential injury of these grafts. The operative procedure is well described and beautifully illustrated.

Who we "are" as professionals is a distillation of our experience and knowledge, and affects how we view problems and solutions to these problems. Perspective is both relative and important. Cardiac surgeons are familiar with looking at the heart from the outside, and one might ask how this surgical team came to this innovative internal repair approach. Are they the first to use an internal approach? No, and in fact the senior author of this commentary used an internal repair approach for left ventricular pseudoaneurysm after mitral valve replacement in $1991 .^{2}$ However, this pseudoaneurysm is larger and farther away from the mitral annulus, where surgeons are more

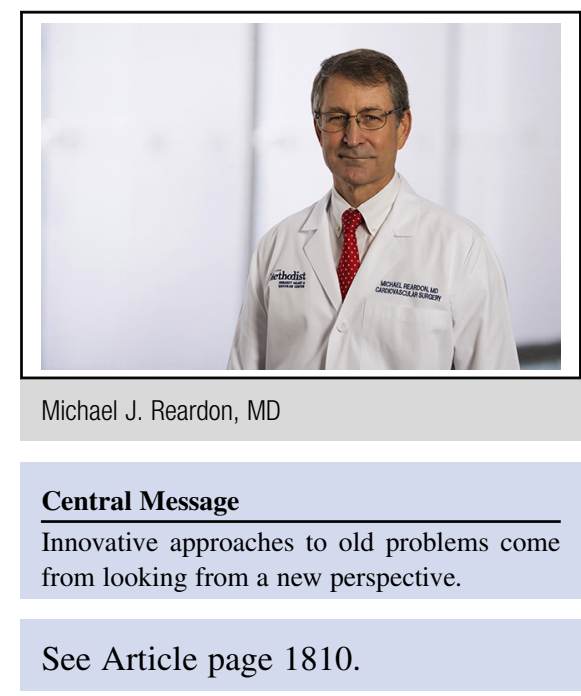

comfortable operating. In addition, we are seeing pseudoaneurysms after a transapical approach to transcatheter cardiac procedures treated successfully with a transcatheter internal repair. ${ }^{3}$ The rapid growth of transcatheter aortic valve replacement has been accompanied by the establishment of well-functioning heart teams. The wellfunctioning heart team combines the knowledge and experience of both interventional cardiologists used to approaching cardiac lesions from the inside out and cardiac surgeons more versed in going from outside in. We see things not as they are but as we are. This blending can change who we "are" and lead, in the right environment, to seeing things in an innovative way and novel approaches to old problems. How long before this team creates a transcatheter approach to a similar problem? From our heart team to yours, congratulations.

\section{References}

1. Charles RMH, Crestanello JA. Transaortic endoventricular patch repair of left ventricular pseudoaneurysm. J Thorac Cardiovasc Surg. 2018;156: 1810-2.

2. Baker WB, Klein MS, Reardon MJ, Verani MS, Zoghbi WA. Reversible cardiac dysfunction (hibernation) from ischemia due to compression of the coronary arteries by a pseudoaneurysm. $N$ Engl J Med. 1991;325:1858-61.

3. Mendiz O, Fava C, Cerda M, Lev G, Caponi G, Valdivieso L. Percutaneous repair of left ventricular pseudoaneurysm after transcatheter aortic valve replacement. Cardiovasc Revasc Med. 2017;18(6S1):30-1. 